\title{
Perceptions of Students' Counselling Experience with Intern Counsellors within a Tertiary Education Setting: A Thematic Analysis
}

\author{
Sarah Forman \\ National Manager of Counselling and Wellbeing \\ SAE Institute (Navitas) \\ Katrina Andrews \\ Research Supervisor and Senior Lecturer \\ Australian College of Applied Psychology (Navitas)
}

\begin{abstract}
Mental health decline and psychological distress is rising among tertiary students' worldwide and is now recognised internationally as an important public health issue. There is a growing demand for campusbased counselling services as evidence suggests that providing on-campus counselling support can significantly support student mental health and wellbeing. In addition, there is a symbiotic demand for counselling students to have the opportunity to integrate their skills through practice with clients. With the increasing demand for universities and tertiary institutes to provide counselling support, the use of graduate level trainees to deliver counselling services could provide an innovative and effective model to cope with high demand in a cost-efficient way. This qualitative research explores the perceptions of students who have sought counselling, delivered by trainee counsellors within a tertiary education setting. A thematic analysis was used to interpret the data from anonymous, semi-structured survey questions. Three predominate themes were identified; 1) positive experiences of counselling were connected directly to the relationship and positive regard that the counsellor fostered; 2) the counselling process supported the clients' autonomy, self-determination and resilience and 3) despite nervousness, clients were surprised by the perceived positive benefits of counselling. A fourth theme identified that a minority of clients need a more experienced therapist to support their needs. This study demonstrated that counselling services delivered by trainee counsellors was perceived as helpful by the majority of students and has implications for improving practice and service availability through the use of trainees within university counselling services.
\end{abstract}

\section{Keywords}

Counselling, student distress, tertiary students, university and tertiary education counselling service, trainees, interns, student counsellors, effective outcomes

\section{Introduction}

This research explored the perceptions of tertiary students who have sought counselling within an oncampus, higher education setting. The counselling was provided by trainee counsellors, 'interns', in their final placement unit of study within Bachelor of Counselling, Graduate Diploma of Counselling or Master of Counselling and Psychotherapy awards. The accredited degree courses were delivered by a higher education provider in Australia. These awards are accredited by peak accreditation bodies within Australia for the discipline of counselling and psychotherapy (PACFA and ACA) and as such require up to 240 placement hours for completion of the award and eligibility for membership. This research explores the clients' experience of the counselling received by the intern counsellors and aims to inform whether such a service is perceived as helpful. It aims to provide greater insight and understanding into the students' experience of their counselling, as well as informing service delivery and practice improvements that may support the use of interns in models of counselling service delivery. With mental health issues and psychological distress continuing to rise among tertiary students' world-wide (Randall \& Bewick, 2016), the mental health of university students is now recognised internationally as an important public health issue. In addition to increased awareness of the benefits of counselling (New, 2017; Predrill et al., 2014) there is a growing demand for campusbased counselling services as evidence suggests that providing on-campus counselling support can 
significantly support student mental health and wellbeing (Stallman \& Bewick, 2018). With this increasing demand for universities and tertiary institutes to provide counselling support, the use of graduate level trainees to deliver counselling services could provide an innovative, and effective model to cope with high demand in a cost-efficient way. However, there is little qualitative research on the clients' perceptions' of their experience with student counsellors.

\section{Background}

\section{Growing decline of mental health of tertiary students.}

A growing body of research suggests that student mental health is declining world-wide, within the tertiary education sector (Storrie et al., 2010). In Australia, research reports consistent and alarming findings in regards to students' mental wellbeing. According to the National Tertiary Student Wellbeing Survey (National Union of Students in collaboration with Headspace, 2016), students are feeling stressed and under pressure. Of the 3,300 students surveyed, one in three students have had thoughts about self-harm or suicide in the last 12 months, $83.2 \%$ felt stressed and $79 \%$ felt anxious, while two thirds reported very high levels of psychological distress and more than half reported having trouble sleeping. Overall, 70\% of students surveyed rated their mental health as "poor" (Kinsella, 2017). This survey represents a large number of students however, sample participants' self selected, therefore a potential bias within the data could make it less reliable.

Similarly, a recent study of students in Victoria revealed that in the past four years almost half reported having consistently poor mental well-being (Cann, 2017). The Victoria University survey was completed by approximately 5000 students annually and was based on the World Health Organisation, Five Well-Being Index (WHO-5) assessment tool, a self-reported measure of current mental wellbeing within a previous timeframe of two weeks. The WHO -5 assessment tool has proven to have good validity in screening for depression and measuring wellbeing outcomes in studies with a range of populations groups, including young adults (Topp et al., 2015). This study found that $71 \%$ of students have experienced some form of emotional illness, including anxiety, depression, and eating disorders, and 43\% reported having poor emotional wellbeing (Cann, 2017). Again, this research sample was self-selected, however the numbers of participants, validity of the assessment tool used and similarities in findings add validity to the findings overall and perhaps balance potential bias.

These trends are consistent with findings in international research. A survey of psychological distress in students across four UK Higher Education Institutions found almost one-third of students reported clinical levels of psychological distress (Bewick et al., 2008), with $8 \%$ of these students reporting moderate to severe or severe levels of distress. The American National College Health Assessment (ANCA), the nation's principal advocate and leadership organization for college and university health, reports annually on data examined from 125,000 students at more than 150 colleges and universities in the United States. In 2013, 31.3\% of students surveyed reported feeling so depressed they were having difficulty functioning and $51.1 \%$ experienced overwhelming anxiety (ANCHA, 2013). The same national survey conducted in 2019 found further significant increases in these figures with $45.1 \%$ of students surveyed reporting feeling so depressed they were having difficulty functioning and $65.7 \%$ reporting overwhelming anxiety (ANCHA, 2019).

According to Cuijpers et al. (2015) this prevalence trend is mirrored by reports of "year over year increases' in students with common mental health problems by the Centre of Collegiate Mental Health (CCMH, 2017), the American College Health Association (ACHA 2009) and the Association for University College Counselling Centre Directors (AUCCCD, 2016). The large numbers of students surveyed points to consistent themes of students in psychological distress throughout the western world.

In addition, there is a growing body of research that supports an emerging trend of tertiary students exhibiting higher rates of psychological distress than those measured in general population groups. 
According to Cvetkovski et al. (2012) and Stallman (2011) there is evidence that tertiary students have a greater level of psychological distress, than non-students. In these two studies the Kessler Psychological Distress Scale 10 was used to estimate the prevalence of moderate and high distress in students compared to general population groups. Both concluded that higher rates of distress were evident in tertiary students compared to the general population groups tested (Cvetkoviski et al., 2012; Stallman, 2011). Thus providing further evidence that warrants university students being classified as an at-risk population. In addition, the implications of both studies highlight the need for early intervention and psychological support for university students to prevent the development of severe mental illness (Stallman, 2011).

\section{Demand and pressure on universities to respond.}

While the mental health of university students is now recognised internationally as an important public health issue (Randall \& Bewick, 2016), universities and tertiary institutes are under increasing pressure to respond to this growing crisis. In recognition of the concern, Higher Education Governance bodies, such as the Tertiary Education Quality and Standards Agency (TEQSA) in Australia, have added mental wellbeing into their standards frameworks. Education providers now need to demonstrate that they are creating environments of wellbeing and safety for all students, 'including those students whose studies are impeded by health issues, including mental health issues requiring access to counselling' (TEQSA, 2015).

It is noted that the majority of literature reviewed identified financial distress as a significant contributing factor towards distress for tertiary students, which further supports the need for education institutions to provide free services to their students. Research conducted by WHO World Mental Health Surveys International College Student Project: Prevalence and distribution of mental disorders (2018), in which 19 colleges across eight countries participated, concluded that the world is contending with increased rates of mental health disorders in students and that available resources are not able to meet demand for on-campus services. This report continues to conclude that the need for mental health services implied by the results of the survey represents a major challenge to higher education institutions further demonstrating the need to explore innovative means to respond to the growing demand.

In the 'Under the radar report' (Orygen, 2017) released by The National Centre of Excellence in Youth Mental Health, it was also highlighted that in Australia and New Zealand counselling service managers and staff are reporting a lack of capacity to respond to demand for services as students' presentations of complex psychological distress increases (Andrews, 2016). There is corresponding financial pressure to provide services to support these complex needs of students within the education sector. This further highlights the increasing urgency of need for greater mental health support for university students.

\section{Beneficial outcomes of counselling for students}

In addition to increased awareness of the demand for mental health support for students there is a small, but growing body of research on the benefits of counselling delivered in the university setting (New, 2017; Predrill et al., 2014). There is also evidence that suggests that providing on campus counselling support can significantly support student mental health and wellbeing (Stallman \& Bewick, 2018; Murray et al., 2015).

Further to research suggesting that students' mental health and wellbeing can be supported and improved through on campus counselling services, there is some evidence to suggest that academic outcomes can also be improved when students get the psychological support they need. Numerous studies have concluded that students who access on campus counselling services not only report high levels of satisfaction, but are also more likely to complete their studies (Cann, 2017; Mooney \& O'Brien, 2010; O'Keefe, 2013; Stallman \& Bewick, 2018). Furthermore, evidence points to the effectiveness of brief interventions delivered by student counselling support services, and in 
particular a stronger link to improved educational outcomes among students who access counselling services (Connell et al., 2008; Murray et al., 2016), including those with disadvantaged socioeconomic circumstances (Stone, Walton, Clark, \& Ligertwood, 2016).

Another study in the United States found that self-reported data from students on academic impact of accessing counselling services, showed that $71 \%$ responded positively (Reetz et al., 2015). While in the UK a study using control groups, the Adult Self Report (ASR) and the Outcome Questionnaire (OQ-45), (Hansen et al., 1996) scores found that compared with the control group, the students who received counselling exhibited lowered distress scores and a significant recovery regarding their progress with their studies (Biasi et al., 2016). Therefore, it is evident throughout the research that on campus, face-to-face counselling interventions are effective and helpful for students in tertiary institutions, both in terms of improved well-being and better study outcomes (Browne et.al., 2017).

\section{Gaps in current research}

\section{How to provide sustainable support for students' mental health and wellbeing?}

While on campus counselling services have increased in the last decade (Grant, 2011) evidencing that there is a need for future research to investigate innovative and sustainable ways to respond to high demand with limited resources (New, 2017). American researchers IIgan et al. (2014) suggest that, "there is a need to explore affordable ways to bolster services for students in need of counselling interventions. One potential solution for managing high demands for services is to utilise graduate level trainees" (p. 229).

There is a symbiotic demand for counselling students to have the opportunity to integrate their skills through practice with clients. Practical placements are a mandatory training component for students studying counselling, providing a valuable opportunity for trainees to self-reflect, practice, and integrate their skills in a real-world counselling setting (Nyman et. al., 2010). Accredited counselling trainee programs need to provide their students with opportunities to practice their counselling skills through internships or work-based placements, in order for students to graduate. National counselling and psychotherapy association bodies such as the The Australian Counselling Association (ACA) and the Psychotherapy and Counselling Federation of Australia (PACFA) require a minimum of 40 hours of face-to-face practice in order for provisional membership to be obtained.

\section{Can interns provide an effective service?}

There is a small, but growing body of research that has examined the client outcomes of counselling provided by interns compared to experienced professionals (Ilgan et al., 2014; Nyman et. al., 2010; Miller et. al., 2016). Researcher and psychotherapist Scott Miller PhD (2016), found that trainee counsellors can score as high in client satisfaction scales as experienced counsellors. Further, research conducted by Ilgan et al. (2014) found that "participants receiving counselling from trainees did not have a different mean symptom improvement score than students receiving counselling from a professional staff member" (p. 236). Similarly, Goldberg et al. (2016) measured therapist outcomes of 170 therapists over an average of 4.73 years, resulting in data that consistently showed very slight or no significant difference in overall outcomes between new and experienced counsellors. There is even some evidence that, "counsellors who display more professional self-doubt, tend to get better outcomes than those who have more professional self-confidence" (Nissen-Lie et al., 2017 p.57).

However, there remains a paucity of research in this area with little or no research conducted in Australia. Of the research that has been completed, it has focussed on the training and specific use of a counselling or supervision model used in intern placement programs (Hackett, 2014). While these subjects are fundamentally important, the focus of this research is on the nuances of the clients' perceptions of the counselling service provided. In additional to further research needed on client outcomes in this area, British researchers Bewick and Randall (2016) suggest that future investigation into the clients' perceptions of their student counselling service would be valuable. Therefore, there 
is a need to increase client - centred data to build a better picture of what is working well and what can be improved in tertiary student counselling services.

\section{Method}

\section{Design}

In order to obtain a deeper understanding of the voice and experience of students accessing the counselling service, a qualitative research design was chosen as being most suitable to obtain personal and rich descriptive data from participants. A qualitative method aligns with wanting to understand the story of the counselling experience as perceived by the clients. Vossler and Moller (2015) state that, "qualitative researchers study individuals and social worlds in their natural setting...they want to explore peoples' stories" (p.164). The intention of the research is to describe the phenomenon of the counselling experience rather than explain it. Punch (2014) states that, "to describe is to draw a picture of what happened, or how things are proceeding, or for what someone of something is like" (p. 15). It is hoped that from this descriptive data more understanding can be gained about what is perceived as helpful or unhelpful by the student clients. This qualitative research has been conducted through the use of an anonymous online survey from which data has been thematically analysed (Please refer to survey questions in Appendix 1).

Thematic analysis was chosen as the most suitable methodology for this research because its highly flexible approach meant it offered a more private and confidential means for participants to engage in the research (Braun \& Clark, 2006). By asking questions on an anonymous survey, rather than conducting interviews for example, this method enabled access to more potential participants and greater anonymity for those who did choose to participate, whilst still enabling rich and detailed data to be captured.

\section{Participants}

All participants were treated in accordance with the NHMRC ethical requirements and their identity was anonymous. Purposeful sampling was used to invite potential participants to engage in the research. Students who were current clients or who were under 18 years of age were excluded. Participants were students who had accessed the counselling service previously for at least 2 sessions and who were not currently accessing the service. To further protect their anonymity, no identifying demographic questions were asked about what campus the students attended or which counsellor they saw. The counsellors of the clients had all completed their placement and were no longer at the institute. There were 19 participants of whom 13 were between the ages of 18 and 25 years and six were over 25 years of age. They were four international students who participated in the survey and 15 Australian students. There were 11 males, five females and three participants who preferred not to disclose their gender. The majority of participants had between three to seven sessions of counselling (12 participants), with five participants having more than 10 sessions and two participants attending two sessions of counselling.

\section{Materials}

Materials used for this research were email and an electronic google form with an open-ended survey questionnaire. The survey questions consisted of 9 demographic and closed questions and 10 open ended long answer questions. These open-ended questions were purpose written for the current study and guided by the known literature, in order to achieve a deep exploration of the research question as is recommended by Jacob and Furgerson (2012). In order to further protect the identity of participants, the demographic questions did not ask for the name of campus location or the name of the counsellor seen. Finally, in order to achieve depth and saturation in participant answers, the survey questions were written to explore the student client's observations of the counsellors use of techniques and skills, their own affect during the sessions, and their overall perception of session effectiveness. 
Participants were also asked for feedback on service improvement and whether they would recommend the service. All materials were stored on a locked USB for storage after the completion of research project as per compliance with the HREA research approval.

\section{Procedure}

The survey was delivered via email to previous students who had accessed the counselling service. An invitation to participate in the survey was sent with a link to a google form questionnaire if the student wished to proceed. A participant information sheet was sent with the email, including instructions on how to withdraw participation at any stage of completing the survey. This could be done by closing the browser at any time. It was clearly stated that once submitted, answers could not be retrieved. Referral information for external services was also given in the invitation email and at the beginning and end of the survey questionnaire. The survey was open for four weeks. A reminder email was sent out after two weeks stating the closing date for participation. Once data saturation occurred a thematic analysis was conducted using the Braun and Clark (2006) model.

\section{Positional statement}

A hermeneutic phenomenological approach was adopted throughout this research. In this case the researcher held the position of supervisor of the counselling service and therefore an invested interest in the outcomes of the clients' experience being positive was explicit from the conception of the project. This was bracketed and examined through regular supervision and discussion with the research supervisor. The hermeneutic approach recognizes that the researcher cannot be rid of his or her 'lifeworld' and that it provides a valuable guide to why a subject is chosen to be researched and then continues to inform the research. According to Neubauer et al. (2019) phenomenology is uniquely positioned to support a researchers' understanding of how to learn from the experience of others, as new meanings and interpretations of experience can be elucidated. The importance of selfawareness and amplified understanding of what the researcher brings to the project was highlighted throughout all stages of this research design and implementation.

\section{Results}

Of the 19 responses to the survey, 15 indicated they had a positive experience and would recommend the service to others. Of the 19 returned surveys $89 \%$ were included in the analysis. Two responses were deemed unsuitable as their comments referred to academic and administrative processes and two responses indicated that the service was not able to help them and that they required a more experienced professional counsellor. This is discussed further as a final theme. Participant views indicated that the relational aspect of the counselling had the most significant impact on their experience and their perceptions of the counselling process.

Three predominant themes emerged from the participants' responses; 1) positive experiences of counselling were connected directly to the relationship and positive regard that the counsellor fostered; 2) the counselling process supported the clients' autonomy, self-determination and resilience and 3) despite expressing nervousness about accessing the service, clients were surprised by the perceived positive benefits of counselling.

A further theme is identified which captures the views of the two participants who reported not feeling satisfied with their counselling experience. This theme, 4) a minority of clients need a more experienced therapist to support their needs, although a minority theme, it is important and worthy of discussion in this paper.

Finally, quotes for inclusion in the analysis were coded to indicate the participant number, then question number (e.g. 12: 11). 


\section{Theme 1. Positive experiences of counselling are connected directly to the relationship and positive regard that the counsellor fostered.}

This theme relates to the approach of the intern counsellor and the relational aspect of the counselling experience. The majority of the participant views in this survey are in accord with the theory of Carl Rogers (1902-1987), humanistic psychologist, and founder of client centred therapy, that a good therapeutic alliance was essential for a positive experience of counselling. This theme was conceptualised from three subthemes: 1.1) feeling listened to and heard; 1.2) feeling cared for; and 1.3) feeling a sense of safety and trust. Each of these are discussed in turn, below.

\subsection{Feeling listened to and heard}

All participants discussed how important feeling listened to was for them and what the counsellor did or didn't do to support this. Participants described what each counsellor did to help them feel listened to, for example, 'She looked me in the eye as I was talking which made me feel like she was listening' (3: 11), and 'The counsellor listened carefully to assess the problem' (18: 12). Participants also described a sense of freedom that came from feeling heard in this way, for example 'it was freeing' (9: 12) and, 'I strongly appreciate how they didn't shut me down or make me feel like I was weak, or an idiot for expressing my distress' (19: 12).

\subsection{Feeling cared for}

Participants who indicated that they were satisfied with their experience described the importance of feeling cared for by the counsellor and that the counsellor's manner or positive regard influenced their experience. For example, participants stated, '(I) felt like I was talking to a real human being who cared', (2:11), 'the counsellor was relaxed, open and kind' (7:11), 'I felt listen to and taken care of' (17:12)', and 'she looked at me with concerned eyes (and)... was attentive to my emotional distress (and showed) steadfast compassion' (19:11).

\subsection{Feeling a sense of safety and trust}

The survey respondents reported aspects of positive regard being shown towards them by the counsellor through the quality of listening, caring and deeply hearing the client that was conveyed. These behaviours created a sense of safety and trust which enabled the respondent to feel vulnerable and to open up. The participants described this as a positive experience that supported their counselling experience and helped them to benefit from it. For example, participants 9 and 17 describe safety and trust; 'I felt safe and seen' (19:15); 'I felt safe and like I could trust him. He listened and really tried to understand' (17: 12) and participants 10 and 18 identified feeling safe enough to feel vulnerable. For example, '(the) counsellor made it comfortable and safe to feel vulnerable...listening, understanding, validating what I was feeling, letting me be OK to cry' (10:12); 'it was a relief to express my vulnerability' (18:10).

\section{Theme 2. The counselling experience supported the client's autonomy, self-determination, resilience and self-efficacy}

Participants reported feeling benefits of counselling when the counsellor supported them to come to their own decisions within the process. The counselling principle of autonomy here, addresses the concept of independence and self-determination (ACA 2005). Counsellor behaviours that underpin 'independence' and 'self-determination' allow the client freedom of choice and action and focus on the responsibility of the counsellor to encourage clients, when appropriate, to make their own decisions and to act on their own values. The data revealed that 15 of the 17 participants felt empowered enough to feel autonomous and to 'lead' the counselling session and to express their authentic thoughts, demonstrating that autonomy and self-determination was supported in the counselling process. 
Resilience is also mentioned as part of this theme as many participants stated that counselling helped them adapt to adversity and manage distress or a stressful period of their lives and continue their studies. Further, a sense of self-efficacy is identified as participants reported feeling an increased capacity to help themselves and make decisions that have positive impacts on them. According to Ozer and Badura (1990), self-efficacy reflects the capacity of individuals to, feel competent and master the ability to engage in behaviours that will help them achieve their goals. Theme 2 is conceptualised with three subthemes, each defined and demonstrated below.

\subsection{Client autonomy and self--determination reinforced}

Fifteen of 19 participants expressed that what helped in counselling was being able to come to their own conclusions about challenges. For example, 'I felt like I had a safe space again and that I would be able to figure it all out.... (the) most important thing was how much I was in control of what I wanted to share and gain from the experience' (11:12), and 'He was able to take my own words and turn them into a strategy for wellbeing' (17:12).

\subsection{Supporting resilience}

Fifteen participants indicated that the counselling had supported them through a difficulty they were experiencing in their lives and enabled them to gain some strength and resilience in relation to it. For instance, participant 16 states that they were, 'very satisfied with the service - it helped me become stronger and more open (16:18)', and participant 14 states, 'It was a critical service to my wellbeing at the time (and) I would not have survived that period of my life without it' (14:14).

\subsection{Sense of self-efficacy}

Participants revealed that having their own autonomy and independence supported in the counselling process was important to them and led to a sense of self-efficacy. For example, 'I felt he helped me to help myself' (17:12). Another participant stated, 'the counsellor's approach was a lot more helpful than previous counselling. I felt like I was doing something proactive ...it made me reflect on experiences and make decisions that benefitted me in the long run' (10:14-17). Participant 19 states, 'my overall experiences have been overwhelmingly positive and empowering' (19:14).

\section{Theme 3. Participants felt anxious about accessing service and were surprised by positive benefits}

Seventeen participants disclosed experiencing a medium to high level of distress from the array of issues which led them to seek counselling. These ranged from significant mental health challenges including suicidal ideation and self-harm, stress, anxiety and depression, to relationship issues, isolation, loneliness and existential issues. A consistent theme throughout the participants' responses was a sense of nervousness, fear and anxiety about accessing the service for the first time. This was accompanied by a lack of certainty about whether it would be beneficial or worthwhile. However, this theme was followed by relief that they had accessed the service and a felt sense of surprise at the unexpected benefits they felt they received.

\subsection{Anxiety and nervous about accessing the service (prior to access)}

Fifteen participants expressed some form of trepidation about accessing the service ranging from nervous and unsure. One participant stated '(I) felt terrified and kind of confused' (13:10), and another (17:10),'I was a bit stressed and afraid'

\subsection{Relieved after accessing counselling}

The majority of participants $(60 \%)$ discussed feeling relieved after they had accessed the service. For example, statements that capture that sense of relief are, 'felt relieved once I sought help' (9:10), and 'it was a major relief to be able to see a counsellor in person' (18:10). 


\subsection{Surprised by benefits and would recommend based on their experience}

Fifteen of 17 participants expressed satisfaction with the service, of which 12 of those expressed feeling somewhat surprised by how beneficial their experience was. For instance, one participant stated, 'It went above and beyond my expectations' (17:13), and another enthused that it 'easily surpassed them (expectations). (I am) 100\% satisfied' (6:13). Another participant states, honestly wasn't expecting it to help, multiple had to encourage me, (I was) shocked when I felt better from it' (3:13-18). Another participant stated that, 'SAE counselling was impressive. I didn't get this kind of support elsewhere professionally I highly recommend and would recommend that students are directed to it immediately if necessary' (14:13-17).

\section{Theme 4. A minority of clients need support from a more experience counsellor}

Two responses expressed not feeling satisfied with the service and needing more than the intern counsellors provided them at this time. Further analysis and discussion is required to understand more about these participants' experiences. These responses were short therefore further opportunity for analysis is limited. Participant number 1 stated that, 'I wouldn't recommend because it didn't help and they don't seem to know what they were doing. Have people who are actual professionals' (1:1618). In addition, when the client did not experience positive regard from the counsellor, their experience was negatively impacted. One of the two participants who stated that they did not find the service helpful stated that 'I felt like I was not listened to' (12: 11).

\section{Discussion}

This research was conducted in order to gain greater insight and understanding of the perceptions of the counselling experienced by students within an on-campus setting. The counselling was delivered by trainee counsellors in their final placement unit of study.

Overall, the responses to the survey used in this study suggest that $88.2 \%$ of participants were satisfied with their counselling experience and perceived it as being helpful and supportive. The first identified theme, 'Positive experiences of counselling are connected directly to the relationship and positive regard that the counsellor fostered', was not surprising due to the large body of research on the therapeutic alliance between counsellor and client. It is widely recognised in counselling and psychotherapy that the therapeutic alliance between client and therapist is being the most important indicator of successful outcomes for the client (Rogers, 1965; Peled- Avram 2015). Thus, this study suggests that trainee counsellors can build a safe, therapeutic alliance with their clients in most cases, despite a lack of depth of experience. The second theme, 'The counselling experience supported the client's autonomy, self-determination and resilience', supports the growing body of research that links on campus counselling to increased student mental health and wellbeing (Stallman \& Bewick, 2018; Murray et al., 2015). This study did not set out to measure resilience; however it did emerge as a theme when data was analysed. This theme would be interesting to explore explicitly in future research and could provide valuable insight into what supports students' experience of their own selfdetermination, resilience and sense of self-efficacy. The third theme of 'Participants feeling anxious about accessing the service and being surprised by positive benefits', alludes perhaps to an ongoing stigma that students might feel about accessing a counselling service. This may also reflect a lack of understanding about the counselling process itself or the human tendency to avoid the experience of vulnerability and the fear of being seen as not coping. This theme could be further explored through examining the accessibility of services and the explicit and implicit messaging that education institutes relay to their students about counselling services.

Finally, the minority of students who felt their complex needs were not addressed in the counselling experience, indicate the need for skilled and experienced professionals to be available and accessible to students wishing to access support in addition to trainee counsellors. Further analysis about the experience of unsatisfied students could be helpful to explore the cultural, demographic and 
professional expertise that the counsellor contributes. Triaging client enquiries or providing preliminary intake sessions might also be examined further in relation to this final theme.

In summary, the research themes go some way towards answering the research question and shedding more light on the clients' experience of the counselling provided by trainee counsellors. These qualitative research findings are consistent with existing literature that supports the premise that on campus, face-to-face counselling interventions are effective and helpful for students in tertiary institutions (Browne et.al., 2017). In addition, this study supports the small, but growing body of research that suggests that trainee counsellors can provide an effective service for these student clients (Ilgan et al., 2014; Nyman, 2010; Miller et. al. 2016) and deserves further exploration within the context of university counselling services both in Australia and internationally.

The findings on the therapeutic alliance were not surprising, however the clients' perceptions of helpfulness being linked to their own sense of autonomy and independence is an area that could be explored further. Practice implications of this research include,

1. assessing how the service is promoted and improving accessibility to remove perceived barriers that students might face,

2. ensuring that services using interns to provide direct counselling have access to support from experienced staff

3. ensuring referrals are made to more experienced staff or those with preferred characteristics (e.g. gender, culture or language) to support more complex presentations and needs,

4. empowering intern counsellors through supervision and training to feel confident about the work they do with clients.

The results of this study suggest that continuing to invest in programs in which intern counsellors can provide counselling to tertiary students can be a helpful solution for both tertiary students, trainee counsellors and institutions alike.

\section{Limitations}

The number of participants was low - only 19 people responded to the invitation to participate in the survey. It is worth noting the COVID - 19 pandemic could have impacted the number of responses received as the survey invitation went out two days prior to unpredicted announcements of campus closures and changes to the modes of delivery for curriculum, which meant students were inundated with emails at the time that the survey was disseminated. This also impacted the data adequacy saturation point as, although one reminder to complete the survey was sent, only two new responses were generated. Had the student cohort not been thrust into a global pandemic, more reminders may have been sent, which in turn may have attracted more survey responses.

Another limitation was the answers obtained in the survey questions were quite short, despite the questions being open ended and encouragement to write a paragraph about their experience of each theme. Deeper understandings and perceptions may have been gained through using interviews rather than anonymous surveys, however in order to protect the identity and maintain the confidentiality of the participants, anonymous surveys were judged to provide the best option.

\section{Conclusion}

From the literature it is evident that there is a mental health crisis happening in our tertiary student population. It is also evident that this is a worldwide phenomenon and while reasons for its occurrence are complex and layered, the support needs are apparent and in no doubt. Although using intern counsellors to provide a service could be considered a risk given their lack of experience, this research provides valuable data on a service that offers an innovative and practical solution to meeting the 
needs of two groups of students. Firstly, the support needs of those attending the counselling service and secondly, the training needs of those delivering it.

From the perspective of those accessing the service, this research provides further evidence that providing on campus counselling services through the use of interns, can be a viable and cost-efficient model for tertiary institutes to consider. This research helps identify what is working well and what could be improved from the students' perceptions, which can help inform, refine and improve service delivery. In addition, the findings of this research are reflective of existing research on the efficacy of trainee counsellors (Goldberg et al., 2016; Ilgan et al., 2014; Nyman, 2010; Miller et. al., 2016) and could potentially inform and influence the teaching and supervision programs of those institutes providing training in counselling.

As a final note, the importance of supervision is not directly explored in this research, but is recognised as a fundamental component to the feasibility of a counselling service delivered by interns. More research to explore this component would provide further insight insight into the efficacy of some ideas discussed. 


\section{References}

American College Health Association, (2019). American College Health Association-National College Health Assessment II: Reference group executive summary, spring 2019. Silver Spring, MD: American College Health Association.

American Counselling Association (2005). Code of ethics. Alexandria, VA

Andrews, A. (2016). ANZSSA Heads of counselling services benchmarking survey 2013 summary report. Journal of the Australian and New Zealand Student Services Association, 47, 96-105. Retrieved from http://static1.1.sqspcdn.com/static/f/1209240/27017819/1462856580353/JANZSSA+April+2016+April+6.pdf ?token=YEVd3gxg2FFjxbppAR7Ux0J8W4A\%3D

Auerbach, R., Mortier, P., Bruffaerts, R., Alonso, J., Benjet, C., \& Cuijpers, P. (2018). WHO world mental health surveys international college student project: Prevalence and distribution of mental disorders. Journal Of Abnormal Psychology, 127(7), 623-638. https://doi.org/10.1037/abn0000362

Australian Counselling Association (2018). Becoming a member. Retrieved from https://www.theaca.net.au.

Bewick, B. M., Gill, J., Mulhern, B., Barkham, M., \& Hill, A. J. (2008). Using electronic surveying to assess psychological distress within the UK student population: A multi-site pilot investigation. E-Journal of Applied Psychology, 4(1), 1-5. doi:10.7790/ejap.v4i2.120

Bewick, B. M., Koutsopoulou, G., Miles, J., Slaa, E., \& Barkham, M. (2010). Changes in undergraduate students' psychological well-being as they progress through university. Studies in Higher Education, 35, 633-645. doi:10.1080/03075070903216643

Bewick, B. Stallman, H. (2018). University students with mental illnesses are falling through the gaps. https://theconversation.com/university-students-with-mental-illnesses-are-falling-through-the-gaps-101290.

Biasi, V., Patrizi, N., Mosca, M., \& De Vincenzo, C. (2016). The effectiveness of university counselling for improving academic outcomes and well-being. British Journal Of Guidance \& Counselling, 45(3), 248-257. https://doi.org/10.1080/03069885.2016.1263826

Bond, T. (2003). Efficacy in evidence - based practice. Clinical Psychology and Psychotherapy, 10, 328 - 336.

Bond, T. (2004). Ethical guidelines for researching counselling and psychotherapy. Rugby: British Association for Counselling and Psychotherapy. Available at www.bcap.co.uk?research/ethical_guidlines.php on 16/6/13.

Braun, V. \& Clarke, V. (2006). Using Thematic analysis is psychology. Quantitative Research in Psychology, 3(2), 77101. doi: 10.1191/1478088706qp063oa

Braun, V. \& Clarke, V. (2012). Thematic analysis. In H. Cooper (Ed.,), APA Handbook of Research methods in Psychology: Vol. 2. Research designs, (pp 57- 91). Washington, DC: American Psychological Association.

Browne, V., Munro, J., \& Cass, J. (2017). Under the Radar: The mental health of Australian university students. JANZSSA-Journal of the Australian and New Zealand Student Services Association, 25(2), 2617.

Cann, G (2017). Almost half of Victoria University students have poor emotional wellbeing. http://www.stuff.co.nz/national/education/98941253/Almost-half-of-Victoria-University-students-have-pooremotional-wellbeing

Connell, J., Barkham, M., \& Mellor-Clark, J. (2008). The effectiveness of UK student counselling services: An analysis using the CORE System. British Journal of Guidance \& Counselling, 36(1), 1-18. doi:10.1080/03069880701715655

Cuijpers, P., Cristea, I. A., Ebert, D. D., Koot, H. M., Auerbach, R. P., Bruffaerts, R., \& Kessler, R. C. (2016). Psychological treatment of depression in college students: a metaanalysis. Depression and anxiety, 33(5), 400414. https://doi.org/10.1002/da.22461

Cvetkovski, S., Reavley, N., \& Jorm, A. (2012). The prevalence and correlates of psychological distress in Australian tertiary students compared to their community peers. Australian \& New Zealand Journal Of Psychiatry, 46(5), 457-467. https://doi.org/10.1177/0004867411435290

Doody, O., \& Noonan, M. (2013). Preparing and conducting interviews to collect data. Nurse researcher, 20, 28-32. EJournal of Applied Psychology, 4(2), 1-5. doi:10.7790/ejap.v4i2.120 
Goldberg, S.B., Rousmaniere, T. Miller, S.D. Whipple, J. Nielson, S.L. William, T. Hoyt, B. Wampold, E. (2016). Do psychotherapists improve with time and experience? A longitudinal analysis of outcomes in a clinical setting. Journal of Counselling Psychology, 63, 1,1-11

Grant, A. (2011). The growth and development of mental health provision in UK higher education institutions. Universities UK/Guild HE working group for the promotion of mental well-being in higher education. Retrieved from http://www.mwbhe.com

Gregersen, A. T., Nebeker, R. S., Seely, K. I., Lambert, M. J. (in press). Social validation of the Outcome Questionnaire: An assessment of Asian and Pacific Islander college students. Journal of Multicultural Counseling and Development.

Hackett, G. (2011). Training counseling students to work more effectively with short-term clients. Published online: 22 June 2011\# Springer Science+Business

Headspace, National Youth Mental Health Foundation, (2016). National tertiary student wellbeing survey. Retrieved from https://headspace.org.au/assets/uploads

Hox, J. J., \& Boeije, H. R. (2005). Data collection, primary vs. secondary. Encyclopaedia of Social Measurement, 1, 593599. Retrieved from: http://joophox.net/publist/ESM_DCOL05.pdf

Ilagan, G., Vinson, M., Sharp, J. L., Havice, P., \& Ilagan, J. (2014). Trainees versus staff: Exploring counseling outcomes in a college counseling center. Journal of College Student Psychotherapy, 28(3), 229-240.

Jacob, S., \& Furgerson, S. (2012). Writing interview protocols and conducting interviews: tips for students new to the field of qualitative research. The Qualitative Report, 17, 1-10. http://www.nova.edu/ssss/QR/QR17/jacob.pdf

Kinsella, L (2017). A crisis of resilience at Australian Universities http://www.news.com.au/lifestyle/health/a-crisis-ofresilience-at-australian-universities/news-story/1f32429892c24d6c9804f48565e3ef47\#sharehash

McKenzie, K., Murray, K., Murray, A., \& Richelieu, M. (2015). The effectiveness of university counselling for students with academic issues. Counselling and Psychotherapy Research, 15(4), $284-288$. https://doi.org/10.1002/capr.12034.

Mcleod, J. (2001). Qualitative research in Counselling and Psychotherapy. London: Sage

Miller, S.D. Owen, J, Wampold, B. E. Kopta, M. Rousmaniere, T. (2016). As good as it gets? Therapy outcomes of trainees over time. Journal of Counselling Psychology, 63, 1, 12-19.

Mooney, A. and O'Brien, M. (2010). Introducing a routine outcome and feedback measure in an Australian University counselling service. Journal of the Australian and New Zealand Student Services Association, 36, 70-86. https://core.ac.uk/reader/143880257

Murray, A., McKenzie, K., Murray, K., \& Richelieu, M. (2015). An analysis of the effectiveness of university counselling services. British Journal of Guidance \& Counselling, 44(1), $130-139$. https://doi.org/10.1080/03069885.2015.1043621

New, J. (2017). Balancing response and treatment. Retrieved from https://www.insidehighered.com/news /2017/01/13/colleges-struggle-provide-ongoing-treatment-demands-mental-health-services-increases

Neubauer, B. E., Witkop, C. T., \& Varpio, L. (2019). How phenomenology can help us learn from the experiences of others. Perspectives on medical education, 8(2), 90-97.

Nissen-Lie, H. A., Rønnestad, M. H., Høglend, P. A., Havik, O. E., Solbakken, O. A., Stiles, T. C., \& Monsen, J. T. (2017). Love yourself as a person, doubt yourself as a therapist? Clinical Psychology \& Psychotherapy, 24(1), 48-60. doi:10.1002/cpp.1977

Nyman, S.J. Nafziger, M. A. Smith, A, Timothy, B (2010). Client outcomes across counselor training level within a multitiered supervision model. Journal of Counselling and Development, 88(2), 204-209.

O'Leary, Z (2010). The essential guide to doing your research project, 2nd ed. Sage.

O'Keefe, P. (2013). A sense of belonging: Improving student retention. College Student Journal (47)4, 1 December 2013, 605-613(9).

Ozer, E. M., \& Bandura, A. (1990). Mechanisms governing empowerment effects: A self-efficacy analysis. Journal of Personality and Social Psychology, 58, 472- 486. doi:10.1037/0022-3514.58.3.472

Pedrelli, P., Nyer, M., Yeung, A., Zulauf, C., \& Wilens, T. (2014). College students: Mental health problems and treatment considerations. Academic psychiatry: The Journal of the American Association of Directors of Psychiatric Residency Training and the Association for Academic Psychiatry, 39(5), 503-11. 
Peled-Avram, M. (2015). The role of relational-oriented supervision and personal and work-related factors in the development of vicarious traumatization. Clinical Social Work Journal, 45, 22-32. https://doi.org/10.1007/s10615-015-0573-y

Psychotherapy and Counselling Federation of Australia (2018). Membership. Retrieved from pacfa.org.au

Punch, K. F. (2014). Theory and method in social science research. In Introduction to social research: Quantitative and qualitative approaches (3rd ed., pp. 13-30). London, England: Sage.

Randall, E. M. \& Bewick, B. M. (2016). Exploration of counsellors' student counselling service, British Journal of Guidance \& Counselling, 44:1, 86-98.

Rogers, C. R. (1965a). The therapeutic relationship: Recent theory and research. Australian Journal of Psychology, 17(2), 95-108.

Royal College of Psychiatrists. (2011). Report on the mental health of students in higher education (Council report CR116; update on report CR112). Retrieved from http://www.rcpsych.ac.uk/files/

Sanders, P. \& Wilkins, P. (2010). First steps in practitioner research: A guide to understanding and doing research in counselling and health and social care. Ross- On- Wye. PCCS Books.

Stallman, H. (2010). Psychological distress in university students: A comparison with general population data. Australian Psychologist, 45(4), 249-257. https://doi.org/10.1080/00050067.2010.482109

Stone, M., Walton, T., Clark, C., \& Ligertwood, L. (2016). The influence of support and development programs and services on the success of university students from low socioeconomic status backgrounds. Journal of the Australian and New Zealand Student Services Association, 24, 25-39. https://janzssa.scholasticahq.com/article/1093-the-influence-of-support-and-development-programs-andservices-on-the-success-of-university-students-from-low-socioeconomic-status-backgrounds

Storrie K, Ahern K, Tuckett A. (2010). A systematic review: Students with mental health problems - A growing problem. International Journal of Nursing Practice. 16: 1-6.

Tertiary Education Quality and Standards Agency (2018). Higher education standards framework. HESF Domain 2: Learning Environment. Retrieved from teqsa.gov.au.

Topp C.W., Østergaard S.D., Søndergaard S., \& Bech P. (2015). The WHO-5 well-being index: A systematic review of the literature. Psychotherapy and Psychosomatics, 84, 167-176.

Ustun, B., Adler, L.A., Rudin, C., Faraone, S.V., Spencer, T.J., Berglund, P., Gruber, M.J., \& Kessler, R.C. (2017). The World Health Organization adult attention-deficit/hyperactivity disorder self-report screening scale for DSM-5. JAMA Psychiatry, 74(5), 520-526.

Vossler, A., \& Moller, N. (2015). The counselling and psychotherapy research handbook. London, UK. Sage Publications Ltd.

\section{The authors may be contacted via}

katrinatravers@gmail.com

\section{Please cite this paper as:}

Forman, S. \& Andrews, K. (2021). Perceptions of students' counselling experience with intern counsellors within a tertiary education setting: A thematic analysis. Journal of the Australian and New Zealand Student Services Association, 29(1), 59-73. https://doi.org.10.30688/janzssa.2021.1.03 


\section{Appendix 1. Survey Questions: Section 2.}

\section{Counselling Service Research}

1.Please confirm that you are over 18 years old and not currently accessing the counselling service

i. Above statement is true

ii. Above statement not true - please close browser and do not complete survey- thank you for your time (mark one only)

\section{First, we want to collect some demographic information....}

2. What is your age range?

i. 18 - 25 years

ii. 25 years and over (mark one only)

3. What nationality are you?

4.What is your gender?

$\begin{aligned} \text { i. } & \text { Female } \\ \text { ii. } & \text { Male } \\ \text { iii. } & \text { X - intersex, other, unspecified } \\ \text { iv. } & \text { Prefer not to say (mark one only) }\end{aligned}$

Please answer the following questions in as much detail as you would like to give....

5. How many times did you access the counselling service?

6. Did you see the same intern counsellor each time?

Yes No (mark one only)

7. If no, how many intern counsellors did you see?

8. Have you ever accessed counselling elsewhere?

Yes No (mark one only)

9. If yes, how would you compare any previous experience with your counselling experience at $* * *$ ? Please summarise.

10. Please summarise your reasons for accessing the service

11. Please describe how you felt when accessing the counselling service for thefirst time.

12. Can you describe what the counsellor did to make you feel comfortable, or not in the sessions?

13. In what way was the counsellor's approach helpful or not?

14. Please explain if and how the service met your expectations.

a. Please summarise your overall experience of the counselling and whether you were satisfied or not with the service.

b. Please describe if you felt the counselling you received was helpful at the time and why.

c. Explain why you would, or would not, recommend this services to other students.

15. Would you access the service again if you needed to?

16. How do you think the service could be improved? Please describe. 